\title{
The oenological interest of fumaric acid: Stop malolactic fermentation and preserve the freshness of wines
}

\author{
A. Morata ${ }^{1}$, M.A. Bañuelos ${ }^{2}$, C. López ${ }^{1}$, S. Chenli ${ }^{1}$, R. Vejarano ${ }^{3}$, I. Loira ${ }^{1}$, F. Palomero ${ }^{1}$, and J.A.S. Lepe ${ }^{1}$ \\ ${ }^{1}$ Chemistry and Food Technology Department - Universidad Politécnica de Madrid. Av. Puerta de hierro, 2, 28040 Madrid, Spain \\ ${ }^{2}$ Biotechnology-Vegetal Biology Department, ETSIAAB, Universidad Politécnica de Madrid. Av. Puerta de hierro, 2, 28040 Madrid, \\ Spain \\ ${ }^{3}$ Faculty of Engineering, Universidad Privada del Norte (UPN), Trujillo, Perú
}

\begin{abstract}
One of the problems related to the increase in average temperatures in the wine-growing regions is the lower accumulation of organic acids in the berries. Wine freshness depends to a great extent on its acidity. Herein, the effectiveness of fumaric acid to inhibit malolactic fermentation or to stop it once initiated is evaluated in order to preserve the malic acid content. Different doses of fumaric acid and $\mathrm{SO}_{2}$ were tested. The ability of these compounds to inhibit bacterial development and stop the malic acid degradation was tested on a red wine of the variety Vitis vinifera L. cv. Tempranillo whose malic acid content was set at $1.5 \mathrm{~g} / \mathrm{L}$. The control wine inoculated with $6 \log \mathrm{CFU} / \mathrm{mL}$ of Oenococcus oeni finished the malolactic fermentation in 12 days. However, the use of doses equal to or greater than $300 \mathrm{mg} / \mathrm{L}$ of fumaric acid delayed the onset of malolactic fermentation for more than 50 days with little degradation of malic acid. In addition, fumaric acid proved to be effective in stopping malolactic fermentation already started where the bacterial count was $7 \log$ $\mathrm{CFU} / \mathrm{mL}$. Fumaric acid can be considered as a potent inhibitor of malolactic fermentation.
\end{abstract}

\section{Introduction}

One of the most notable changes in climate change is the widespread rise in average temperatures. Associated with this increase in temperatures in wine-growing areas, the musts have increasingly higher sugar contents and lower organic acids. The freshness of wine is mainly related to moderate alcohol content, high acidity and primary aromas reminiscent of grapes [1]. Therefore, finding new strategies to preserve the freshness of the wines produced in this climate scenario is important to respond to current consumer demand.

Along with the precipitation of tartaric salts caused by the increasing concentration of ethanol in the fermentation media, malolactic fermentation (MLF) is one of the main responsible for the decrease in the acidity of the must in the winemaking process. This loss of tartaric and malic acids, as major contributors to the total acidity of the wine, greatly affects the decrease in freshness in wines.

Traditionally, the oenological additive most commonly used to prevent the activity of lactic acid bacteria (LAB) is sulphur dioxide [2]. As alternative to $\mathrm{SO}_{2}$, the inhibitory effect of fumaric acid on the growth of LAB affecting the biosynthesis of pyrimidines has long been known $[3,4]$. This bactericidal effect of fumaric acid has been described when added after alcoholic fermentation at doses between 0.4 and $1.5 \mathrm{~g} / \mathrm{L}$ [5]. However, depending on the strain, if the LAB has fumarase activity, it may not be affected by the inhibitory effect of fumaric acid, as well as if residual yeasts able to metabolize it remain in the wine [4].

In addition to the inhibitory effect on malolactic fermentation, the addition of an organic acid could sensorially modify the wine depending on the dose used, since the $\mathrm{pH}$ of the wine may be slightly lowered. Along with this and with less use of sulphur dioxide, other wine quality parameters such as colour intensity and anthocyanin profile could also be affected. Some authors have reported an acidifying power similar to or slightly higher than citric acid [6].

The main objective of this study is to avoid the transformation of malic acid and thus preserve the freshness of wines made in warm areas. The effectiveness of different doses of fumaric acid has been checked in MLO selective media and wine, both to prevent the development of malolactic fermentation and to stop it once started.

\section{Materials and methods}

Different doses of fumaric acid (150, 300, 600, 900 and $1200 \mathrm{mg} / \mathrm{L}$ ) were tested to act as an inhibitor of malolactic fermentation in MLO selective media and red wines with malic acid concentrations higher than $1.5 \mathrm{~g} / \mathrm{L}$. The initial $\mathrm{pH}$ in both media was 4.8 and 3.8 , respectively. Those media were inoculated with $6 \log \mathrm{CFU} / \mathrm{mL}$ of Oenococcus oeni (strain Alpha, Lallemand Inc.), population measured by optical density (OD) at $600 \mathrm{~nm}$ and plate counting. All treatments were performed in triplicate and $\mathrm{SO}_{2}$ was used as a benchmark for LAB inhibition (doses of potassium metabisulfite tested: 25,50 and $100 \mathrm{mg} / \mathrm{L}$ ).

The development of MLF was followed by spectrophotometric analysis of malic and lactic acids using a Biosystems Y15 enzymatic multianalyzer equipment. Moreover, viable bacterial counts were performed throughout the study by plate counting of the suitable dilution. 
A

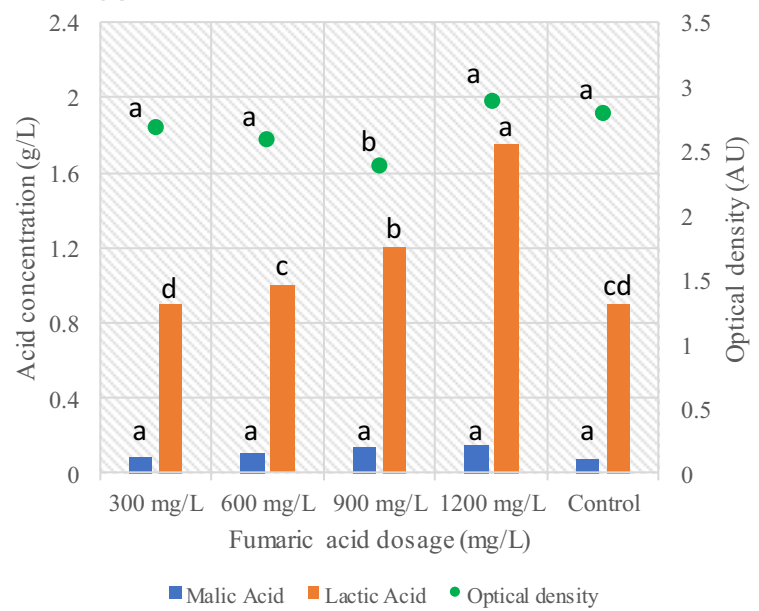

B

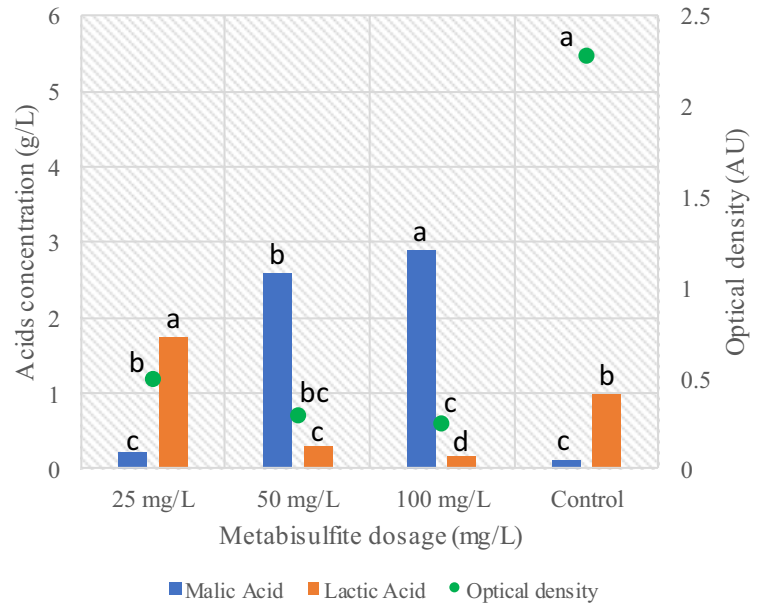

Figure 1. Optical density and final concentrations of malic and lactic acids 5 days after inoculation of MLO media with $2 \times 10^{7} \mathrm{cfu} / \mathrm{mL}$ O. oeni. A: culture media added with fumaric acid; B: culture media added with potassium metabisulfite. In both tests there is a control treatment without addition of inhibitors. Different letters in the same series indicate significant statistical differences $(p<0.05)$.

\section{Results and discussion}

As mentioned above, the addition to wine of an organic acid such as fumaric acid, in a substantial amount of the order of hundreds of $\mathrm{mg} / \mathrm{L}$, could have an impact on the acidity of the wine. However, in general, under the conditions of this assay, only a slight reduction in $\mathrm{pH}$ was found and apparently with no major consequences on the sensory quality of the wine (data not shown).

As for the inhibitory effect, in the MLO medium tests, none of the assayed doses of fumaric acid was able to stop the growth and metabolism of lactic acid bacteria (Fig. 1A). Interestingly, higher doses of fumaric acid promoted greater lactic acid synthesis, starting from the same malic acid content in the culture medium $(2.5 \mathrm{~g} / \mathrm{L})$. Therefore, different metabolic pathways may have been followed for the synthesis of this acid. In future trials, it would be interesting to monitor the concentration of fumaric acid throughout malolactic fermentation to rule

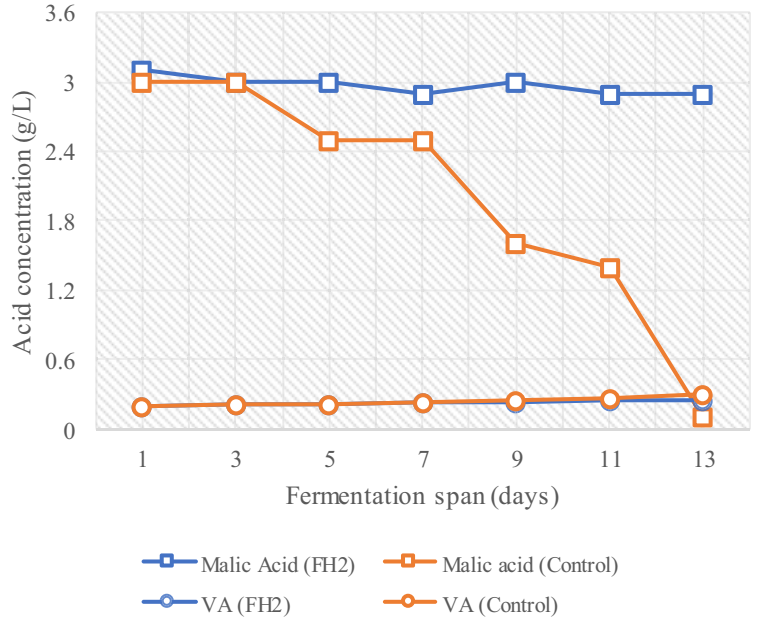

Figure 2. Evolution of malic acid concentration $(\mathrm{g} / \mathrm{L})$ and volatile acidity ( $\mathrm{g} / \mathrm{L}$ acetic acid) along spontaneous malolactic fermentation carried out at $22^{\circ} \mathrm{C}$ in red wines dosed with $600 \mathrm{mg} / \mathrm{L}$ of fumaric acid (Source: personal communication from Elena Adell of the Pernod Ricard Bodegas group).

out its transformation into malic acid by the fumarase activity of certain strains of lactic acid bacteria [4]. It appears that without the synergistic effect of low $\mathrm{pH}$, fumaric acid is unable to exert any bactericidal or bacteriostatic activity. In contrast, in the potassium metabisulfite trial, doses of $50 \mathrm{mg} / \mathrm{L}$ were sufficient to stop bacterial activity, significantly decreasing the LAB population (Fig. 1B).

When fumaric acid was added to wine after completion of alcoholic fermentation, the inhibitory effect on the LAB population was observed for doses of fumaric acid equal to or greater than $300 \mathrm{mg} / \mathrm{L}$. In this case, the starting $\mathrm{pH}$ in the wine was 3.8, and this could have helped to stop the malolactic fermentation. Similar results were obtained by other research groups (Fig. 2). Another interesting finding was the possibility to completely stop the malolactic fermentation once started (initial content of malic acid degraded by $30 \%$ ) with a lactic acid bacteria population of $10^{7} \mathrm{cfu} / \mathrm{mL}$ by adding $600 \mathrm{mg} / \mathrm{L}$ of fumaric acid (data not shown). Comparatively, the control treatment (without inhibitor addition) finished the malolactic fermentation without problems in 12 days, completely transforming the malic acid initially present in the wine.

On the other hand, as expected, the use of potassium metabisulfite totally prevented the onset of malolactic fermentation at the two higher doses tested (data not shown). Despite the great effectiveness of this oenological additive as an antimicrobial, its use has been much questioned in recent years by the increasing allergic sensitivity among consumers.

\section{Conclusions}

Fumaric acid could be an interesting oenological additive capable of inhibiting the growth of lactic acid bacteria or stopping a malolactic fermentation once started. However, it appears that combination with a low $\mathrm{pH}$ medium is necessary for its effective use as an antibacterial. Consequently, this technological strategy allows the production of fresh wines with microbiological stability and low sulfur dioxide requirements. 


\section{References}

[1] A. Morata, I. Loira, J.M. del Fresno, C. Escott, M.A. Bañuelos, W. Tesfaye, C. González, F. Palomero, J.A. Suárez Lepe. Adv. grape and wine biotechnol. EDP IntechOPEN (to be published)

[2] D. Wibowo, R. Eschenbruch, C.R. Davis, G.H. Fleet, T.H. Lee. Am J Enol Vitic. 36, 302 (1985)
[3] D.R. Cofran, B.J. Meyer. Am. J. Enol. Vitic. 21, (1970)

[4] T. Henick-Kling, Wine Analysis (EDP Springer, 1988), p. 276

[5] R. Bauer, L.M.T. Dicks, S. Afr. J. Enol. Vitic. 25, 74 (2004)

[6] A. Morata, M.A. Bañuelos, C. López, R. Vejarano, S. Chenli, J.A. Suárez-Lepe, Proceedings of $41^{\circ} \mathrm{OIV}$ Congress -Punta del Este (Uruguay) 